DOI https://doi.org/10.18551/rjoas.2017-01.18

\title{
AN ECONOMIC RESPONSE OF EXPORT PERFORMANCE AND COMPARATIVE ADVANTAGE OF RICE TRADE BETWEEN CHINA AND VIETNAM
}

\author{
Ha Trinh Thi Viet, Li Shuang, Rasheed Rukhsana, Ishaq Mazhir Nadeem*, \\ Faiz Muhammad Abrar \\ College of Economics and Management, Northeast Agriculture University, Harbin, China \\ *E-mail: mazhir.nadeem@yahoo.com
}

\begin{abstract}
Rice is an important crop that fulfill the domestic food requirements and alsoa source to earn foreign exchange for the economy. This particular study was conducted with an objective to explore the rice export trends between China and Vietnam. Another major objectivewas to assess the export competitiveness and concentration commodity among cerealsfor both countries. For the research analysis, time series data from the year of 1961 to 2013 regarding rice production,cultivated rice area, rice export quantity and value were processed to calculate the compound growth, instability and direction of export.Results of the trend analysis demonstrated that Vietnam export of rice may increase in coming years and for the case of China, the export of rice may decrease in future. The growth rate analysis of both countries suggests that export quantity of rice were found to be $2.70 \%$ (China) and $6.10 \%$ (Vietnam).In terms of instability, during the period-I China was more instable as compared to Vietnam in terms of quantity and value, while during the period-II China export of rice was more stable than Vietnam. The direction of trade between both countries presented significant results as compared to the other neighboring countries. The nominal protection co-efficient (NPC) for export of rice from Vietnam were found to be lower than unity, which explained that Vietnam rice is favorable export commodity than China.
\end{abstract}

\section{KEY WORDS}

Export performance; production response;trade instability; trend analysis; China; Vietnam.

In 2004 the General Assembly of United Nations (UNO) had declared rice as an international year of rice.This happens because almost half of the world's population consumed rice as staple food in their cuisine. For developing countries rice is a major source of foreign earnings. According to FAO (2013) the Thailand and Vietnam were the largest rice exporters and these countries contributed for more than $50 \%$ in world rice exports. Food crops have beenconsidered the most important sector of Vietnam economy and rice crop accounts for 85 percent in it. After 1991, the relationships and cooperation betweenChina and Vietnam dramatically improved which subsequently offered trade benefits between two neighboring countries. After undergoing througha series of policy reforms during the past few decades, the pattern of rice production and trade had significantly changed between China and Vietnam. To explore the precise impacts of these policy reforms on trend and instability for rice export, this study was carried out by analyzing the time series data of rice trade. The particular objectives of this research article were to conduct a trend analysis for rice exports between China and Vietnam; estimate the level of rice export instability; estimate the export competitiveness and finally analyze the inward/outward direction of rice trade betweentwo countries.

\section{MATERIALS AND METHODS}

Data Source. In order to examine the rice export performance and competitiveness, the trade period selected for data set was started from 1961 to 2015 and the covering period was segmented into two halves. The first period-I was comprised from 1961 to 1985 and the second period-II was from 1986 to 2015. Another data set required for assessing the commodity concertation and trade direction between two countries were from 2000 to 2015 . 
Annual data based on rice exports in quantity and value terms, the unit value of exports and the domestic and international prices were also collected. The major source of these data collection was from United Nation (UN) Comtrade data set webpage (http://comtrade.un.org/data/). Secondly, national trade publication of China and Vietnam also used for data validations. Furthermore, certain other trade magazines of leading exporting agencies were also consulted for making a fact based study.

Analysis Techniques:

Compound Annual Growth Rate. The export performance and export competitiveness of rice were calculated by Chan (2009) procedure which is utilized to estimate the compound annual growth rate. The formula for measuring the annual compound growth rate for rice export quantity and value can be written as:

$$
C A G R=\left(\frac{\text { Ending value }}{\text { Begining value }}\right)^{\left(\frac{1}{\text { no.of years }}\right)}-1
$$

where: CAGR indicates the compound annual growth rate for commodity.

Coppock's instability index. According to Coopock (1977) the instability in export process hamper the economic development process. He proposed an estimation technique known as Coopock, s instability index that measured the variation and instability in exports. Algebraically Coopock, $s$ formula can be expressed as:

$$
\begin{aligned}
& \text { Coppock's instability index }=\mid \text { Anti } \log \sqrt{\log V}-1 \mid \times 100 \\
& \log V=\frac{1}{n-1}\left[\sum\left(\log x_{t+1}-\log x_{t}\right)-\frac{1}{n-1} \sum\left(\log x_{t+1}-\log x_{t}\right)\right]
\end{aligned}
$$

where: Xt denotes the exports value in a particular year " $t$ "; $n$ represents the total numbers of years covering a trade period.

Markov Chain Analysis. Markov chain model was applied to examine the nature of structural change in rice exports. The elements of transitional probability matrix "Pij" describe the nature of probability that exports of commodity (rice in our case) will switch from country ' $i$ ' to country ' $j$ ' over the time. The probability of a country retaining its market share is revealed by the diagonal elements $\mathrm{Pij}$, which in other words elucidate the loyalty of an importing countryto the exports of a particular country. In current context, the structural change was treated as a random process between China and Vietnam whilethe figures of average exports of rice from Vietnam to China for the period of 2000 to 2015 were administered for analysis. Algebraically Markov chain modelcan be expressed as:

$$
E_{j t}=E_{i t-1} P_{i j}+e_{j t}
$$

where: Ejt denote the exports of rice from Vietnam to the jth country during the year't'; Eit-1 denote export volume to ith country during the year't-1'; Pij denote the probability of exports that will shift from ith country to jth country; ejt represent the error term; $r$ denote the number of importing countries.

Nominal Protection Co-efficient (NPC). In context of free trade environment and to measure the competitive advantage of rice Nominal Protection Coefficient (NPC) was worked out.NPC represent the ratio of domestic rice price to the world reference price and it gave the extent of competitive advantage of rice export (Gonzales 1993).If the NPC is less than unity, the commodity is treated as globally more competitive.

$$
N P C=\frac{P_{d}}{P_{b}}
$$


where: $\mathrm{Pd}$ denote the domestic wholesale rice price; $\mathrm{Pb}$ represent the world reference rice price.

Measures of Concentration. In the present context of rice trade with Vietnam, the trading partners will be assumed as individual elements. The share ofthese individual elements was used to work out the concentration measures. Let $m$ represent the number of trading partners with Vietnam and qitdenotes the volume ofexports or imports from ith partner country at time t.Then sum of qit from 1 to $\mathrm{m}$ countries will be qt. The exports or imports share of each country for that group of commodity for the year't' could be written as:

$$
\begin{aligned}
p_{i t} & =\frac{q_{i t}}{q_{t}} \\
i & =1, \ldots, m \text { and } t=1, \ldots, T
\end{aligned}
$$

The Hirschman-Herfindahl Index $(\mathrm{HH})$ simply consists of the sum of pits weighted by themselves(Nauenberg et al. 1997):

$$
H H_{t}=\sum_{i=1}^{m} P_{i t}^{2}
$$

The $H H$ index lies between $1 / \mathrm{m}$, the case where all $p_{i t} s$ are equal, and 1 , where there is only one $p_{i t}$, implying that $q_{i t}=q_{t}$.

\section{RESULTS AND DISCUSSION}

Outcomes of Trend Analysis for Rice Export between Vietnam and China. In 1961 the area under rice cultivation was $4744(000 \mathrm{Ha})$ and the production of paddy rice was 8997.40 $(000 \mathrm{t})$, as well as the production of milled rice was $6001.27(000 \mathrm{t})$. In 2015 the area of cultivation increased up to $7816.48(000 \mathrm{Ha})$ and the production of paddy and milled rice also increased an average of $21441.16(000 \mathrm{t})$ and $14004.12(000 \mathrm{t})$, respectively. There was increased in area $3158.81(000 \mathrm{Ha})$ and both kind of rice (paddy and milled) $58416(000 \mathrm{t})$ from 1961 to 2015 . Meanwhile, the world wide export of rice increased from $182.25(000 \mathrm{t})$ to 3939.08 (000 t)(FAO 2015).

To find the trend in export of rice between two countries, the non-parametric regression analysis was used. The results were derived for the period of 1961 to 1985 and denote that the trend of export was constant but after 1985 the export of rice increased. To initiate the country's integration process with world economy, Doimoi reforms were launched in 1986. These policies encouraged the development in agricultural sector and resultantly the rice production increased to a greater extent (Yearbook 2012). During analysis the value of coefficient of regression R2 was found 0.90 (Fig. 1).

The analysis was also carried out to find the export performance of the neighboring countries. Our analysis results indicate that export of rice from Vietnam to China showed a significant positive trend, while Cambodia and Thailand trend curve gradual decreased with a coefficient of regression $\left(R^{2}\right)$ value $0.73,0.74$ and 0.09 , respectively.

Overall, the results showed an increase in trends of rice export between Vietnam and neighboring countries. The co-efficient of regression value was found 0.72 .

The non-parametric trend analysis for export of rice from China was also calculated to assess the performance of rice export. The trend line indicated that the export of rice had been decreased in last ten years as compared to Vietnam. The area of cultivation increased by $22 \%$ compare to Vietnam. This decrease in export of rice was due to the other substitute trading, changing rates of fluctuation and increase in domestic consumption. During analysis the value of co-efficient of regression $\left(R^{2}\right)$ was found 0.23 . 


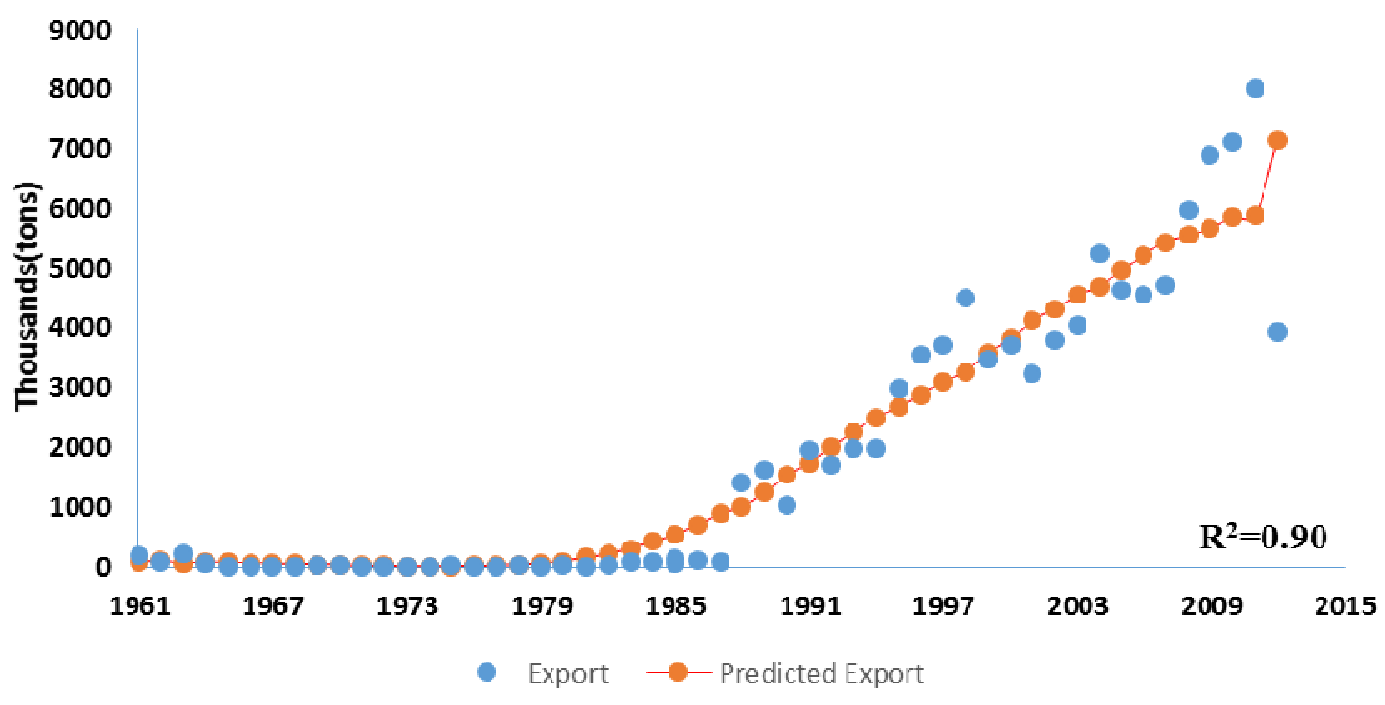

Figure 1 - Trend of rice export from Vietnam (1961-2015)

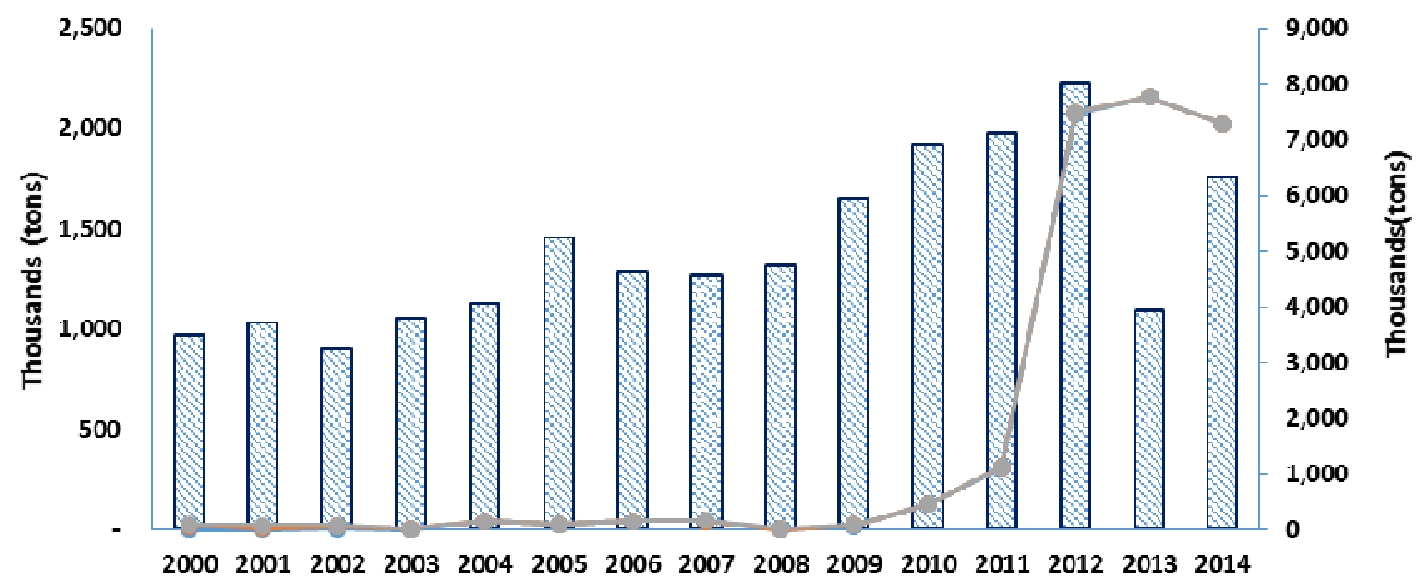

Figure 2 - Export performance between Vietnam and neighboring countries

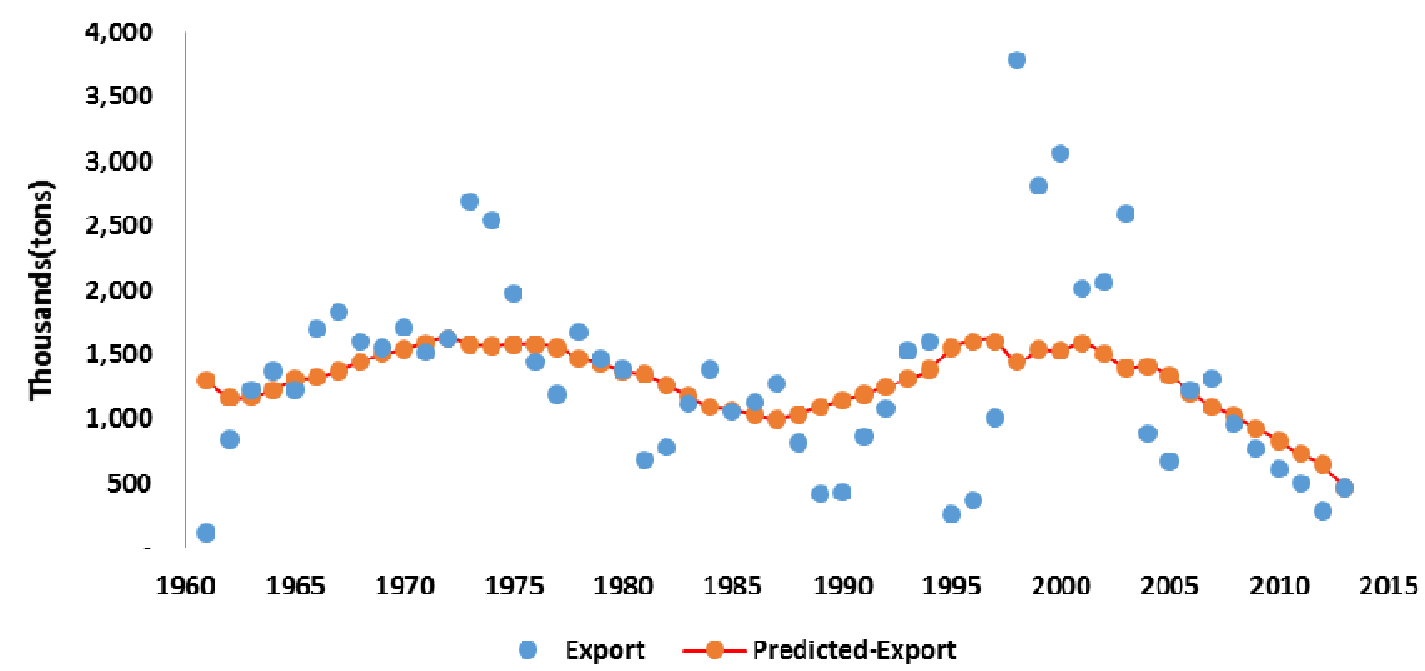

Figure 3 - Trend of rice export from China (1961-2013) 


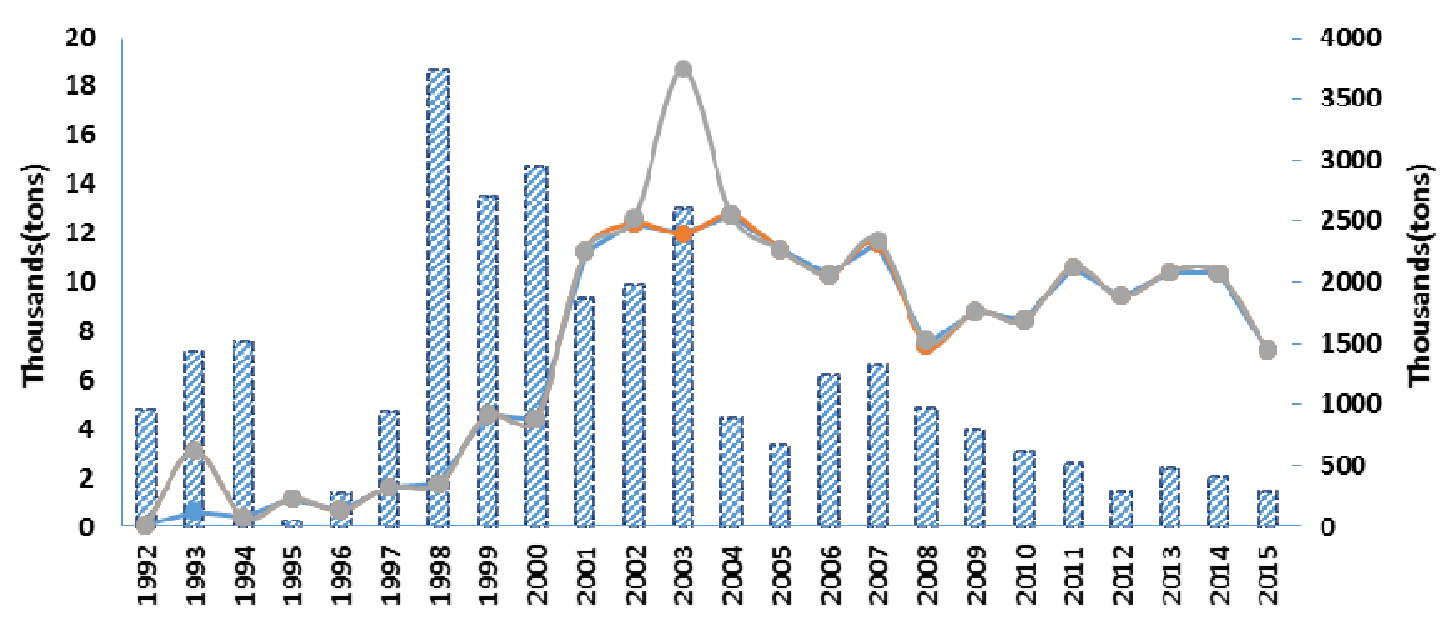

E27221Total-Export World - - Vietnam -Cambodia - Thailand

Figure 4 - Export performance between China and neighboring countries

Figure 4 explained about the export scenario from 2003 towards the world, a gradual decrease in export of china had been observed. The results also indicated that the export trends toward neighboring countries were significantly negative. Overall, the decreasing trends were found during the analysis. The value of the coefficient of regression (R2) was found 0.34 during analysis.

Outcomes of Compound Annual Growth Rate (CAGR). Table-1 represented the results for analysis of compound growth rate between China and Vietnam. In period-I CAGR of China was $(9.7 \%)$ and Vietnam was $(-4.60 \%)$, respectively. Vietnam CAGR was negative due to political unrest and China was becoming stable after political stability particularly after 1981. In period-II China CAGR was negative due to less rice export and high domestic consumption as well as the occurrence of seasonal flood situation. These circumstances resulted low export volume of rice, while in the case of Vietnam after 1975 the political situation became stable, the volume of exports from the country also increased. Therefore, under stable economic conditions a sharp increase in exports of rice had been observed during the preceding years.

Table 1 - Compound growth rate

\begin{tabular}{|c|c|c|}
\hline Time line & China & Vietnam \\
\hline Period-I & $9.7 \%$ & $-4.60 \%$ \\
\hline Period-II & $-3.0 \%$ & $13.40 \%$ \\
\hline Overall & $2.70 \%$ & $6.10 \%$ \\
\hline
\end{tabular}

Overall, the overall CGR of the export quantity of rice were found to be $2.70 \%$ (China) and $6.10 \%$ (Vietnam) which states that there was an increase in the prices of rice in the international market.

Findings of Cop pock's Instability Analysis. The Cop pock's instability index was applied to estimate instability trend of rice trade between China and Vietnam for the two periods. Period-I for Vietnam from 1961-1985 and 1986-2015 before and after the Doimoi reforms. For China same time line was assumed to find the export differences during for both time periods.

Table 2 - Cop pock's instability analysis

\begin{tabular}{|c|c|c|c|c|}
\hline \multirow{2}{*}{ Particulars } & \multicolumn{2}{|c|}{ China } & \multicolumn{2}{c|}{ Vietnam } \\
\cline { 2 - 5 } & Period-I & Period-II & Period-I & Period-II \\
\hline Quantity & 57.24 & 10.38 & 37.86 & 49 \\
\hline Value & 66.04 & 40.79 & 13.93 & 43.72 \\
\hline
\end{tabular}

Source: Authors data analysis results, 2016. 
The instability of export quantity of rice from China in period-1 (57.24) is higher than Vietnam (37.86), that indicated that during this period China faces more restrictions and decrease in demand as compared to Vietnam. For the period-II Instability of rice export quantity of China (10.38) is lower than Vietnam (29).That's mean during this period the fluctuation and growing demand influenced by new policies and restrictions for Vietnam as compared to China.

The estimation of instability for export value, during period-I for China was 66.04 that is much higher than Vietnam (13.93) (Table-2). This implies that China faces many restrictions than Vietnam. In period-II the instability in export rice values was (40.79) and Vietnam was (43.72). This means that after 1986 China received stability in export value, while in Vietnam production and export of rice was increased as compared to China which showed that fluctuations in prices resulted in higher instability as compared to China.

\section{Findings of Markov Chain Analysis}

The direction of trade of China and Vietnam to adjoining countries had been presented in Table-3.It can be perceived that the probability of direction of thetrade from Vietnam to China was stable. China was found a stable importer of rice from Vietnam with gained share of $99.9 \%$ as compared to neighboring countries such as Cambodia, Laos and Thailand. These trading partners were not a stable importer because these countries had been pooled under the category of other countries.

Table 3 - Direction of trade from Vietnam for export of rice (quantity), 2000-2015

\begin{tabular}{|c|c|c|c|c|}
\hline $\mathrm{n} / \mathrm{n}$ & China & Cambodia & Laos & Thailand \\
\hline China & $99.9 \%$ & $0.5 \%$ & $0.4 \%$ & $0.0 \%$ \\
\hline Cambodia & $0.5 \%$ & $0.0 \%$ & $0.0 \%$ & $0.0 \%$ \\
\hline Laos & $0.4 \%$ & $0.0 \%$ & $0.0 \%$ & $0.0 \%$ \\
\hline Thailand & $0.0 \%$ & $0.0 \%$ & $0.0 \%$ & $0.0 \%$ \\
\hline
\end{tabular}

Source: Authors calculations, 2016.

Overall, the results showed that export of rice between China and Vietnam is stable and in future these two countries could be one of the most stable traders of rice among each other.

Outcomes of Nominal Protection Co-efficient (NPC). The nominal protection co-efficient for export of rice from Vietnam to China was found to be lower than unity as shown in Fig. 5. The results implied that rice proved as a good exportable agricultural commodity. It was also observed through the foregoing results that indicated rice was price competitive enough in the international market. Furthermore in coming years, for domestic industry expansion the rice trade showed the existence of vast potential.

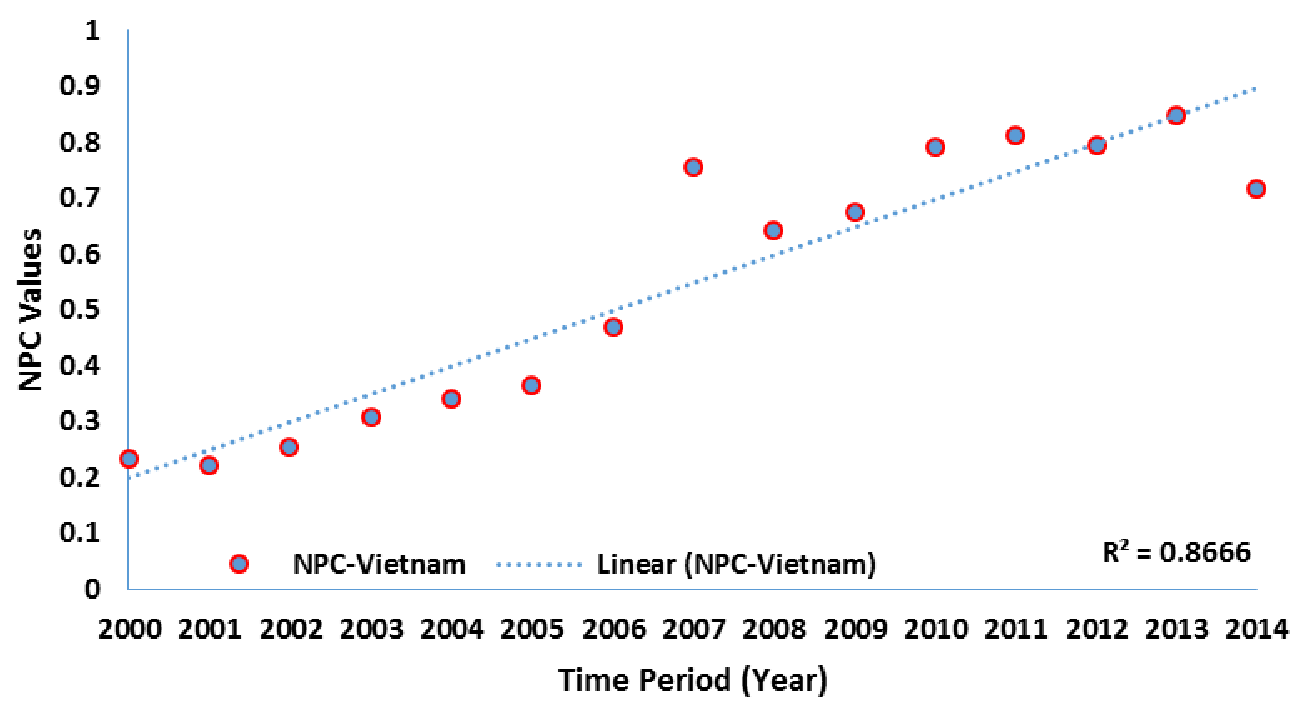

Figure 5 - The nominal protection coefficients for export of rice from Vietnam 
The nominal protection co-efficient for export of rice from China was not found to be lower than unity as shown in Fig. 6. Most of the years were found greater than unity, while the year 2003, 2004,2011 and 2014 were found lower than unity, during this period the export of rice was higher as compared to other years from 2001-2014. The trend of export of rice from China already discussed, which means the export of rice from China may decrease in next few years due to weather, high domestic consumption for a larger population or demand of other countries.

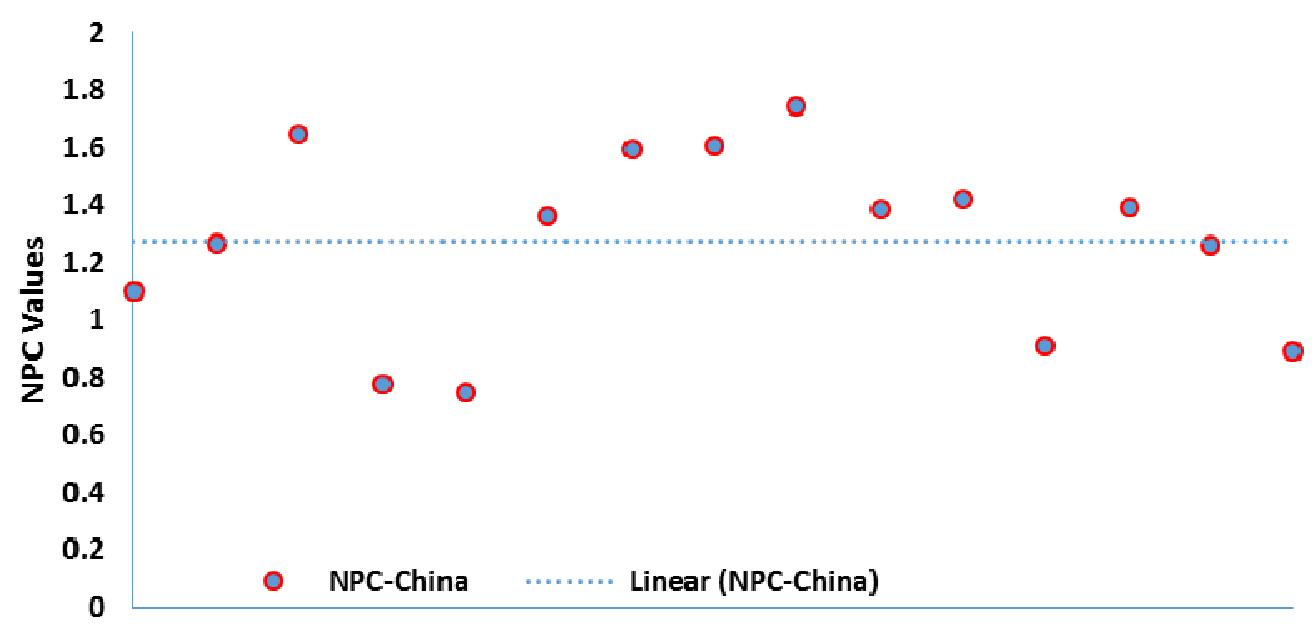

200020012002200320042005200620072008200920102011201220132014

Time Period (Year)

Figure 6 - The nominal protection co-efficients for export of rice from China

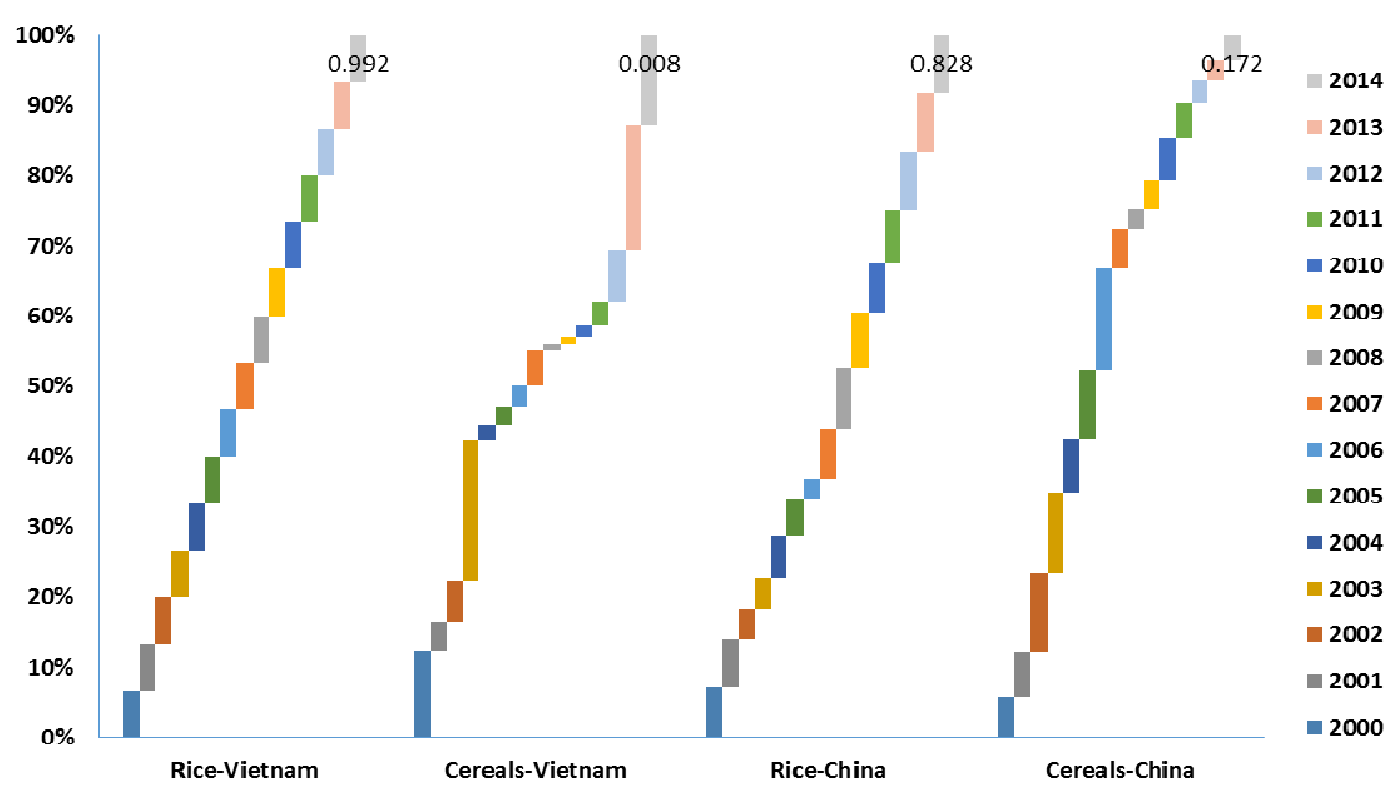

Figure 7 - Comidity concentration

The commodity concentration. Figure 7 shows that the concentration of Vietnam rice as compared to China rice stable in all the time period, while china rice showed the fluctuations from 2000 to 2006. The commodity values increasing and decreasing pattern were found during the time scale. The concentraion of Vietnam rice among the cereals was found higher duirng all the time period. The concentration of China cereals was higher in the begening of the time period, while after it loose its concentration. 


\section{CONCLUSION}

This comparative study was carried out with a focus to measure the performance of rice export between China and Vietnam. On the basis of analysis it was observed that the rice area and yield in Vietnam showed a continuous increase; whereas in the case of China increase in domestic demand was observed. The trade volume had also been increased and this increase had been the result of the green revolution, the introduction of new rice varieties with higher promising yields, better supply of agricultural inputs, a sharp increase in the international rice prices and many other factors. The privatization of the export sector of rice has also helped a lot to promote rice exports from Vietnam which motivated farmers to grow rice as the better prices were expected. The trend analysis indicated that Vietnam export of rice may increase in next few years and in the case of China the export of rice may decrease in future. The growth rate analysis of both countries suggests that export quantity of rice were found to be $2.70 \%$ (China) and $6.10 \%$ (Vietnam) which states that generally, an increase in the prices of rice in the international market.

In terms of instability, during the first period, China was more instable as compared to Vietnam in terms of quantity and value, while during the period-II China was more stable than Vietnam.

The direction of trade between both countries showed the significant results as compared to other neighboring countries. The nominal protection co-efficient for export of rice from Vietnam were found to be lower than unity, while for China most of the year was found greater than unity. This showed that the export of rice from Vietnam is a good exportable product as compared to China. The commodity concentration of Vietnam rice was more stable among the cereals than China. China rice concentration showed the instable concentration as compared to Vietnam. Overall rice growing area in Vietnam was lower as compare to China. In order to bridge the gaps of production area and yield, several steps can be taken. For this purpose stable performing varieties can be introduced and as well as the hybrid rice varieties give more production. The effective measures to prevent the weeds can be taken to increase the production and reduction of the losses. Better irrigation facilities can also be very useful to increase the production and yield. The reduction in export restrictions between two trading partners can further improve the situation.

\section{REFERENCES}

1. Chan, E. (2009). Harvard Business School Confidential: Secrets of Success. John Wiley \& Sons.

2. Cleveland. W.S., Devlin, S.J. (1988). Locally weighted regression: an approach to regression analysis by local fitting Journal of the American Statistical Association 83: 596-610.

3. Coppock, J.D. (1977). International trade instability. Saxon House.

4. FAO. (2015). FAOSTAT database.

5. Gonzales, L.A. (1993). Economic incentives and comparative advantage in Indonesian food crop production vol 93. Intl Food Policy Res Inst.

6. Hiscott, R.N. (1982). Markov chain analysis Mathematical Geology 14: 543-544.

7. Nauenberg, E., Basu, K. Chand, H. (1997). Hirschman-Herfindahl index determination under incomplete information Applied Economics Letters 4:639-642.

8. Yearbook, S. (2012). Statistical yearbook Hue city's Statistical Office, Hue, Vietnam. 